
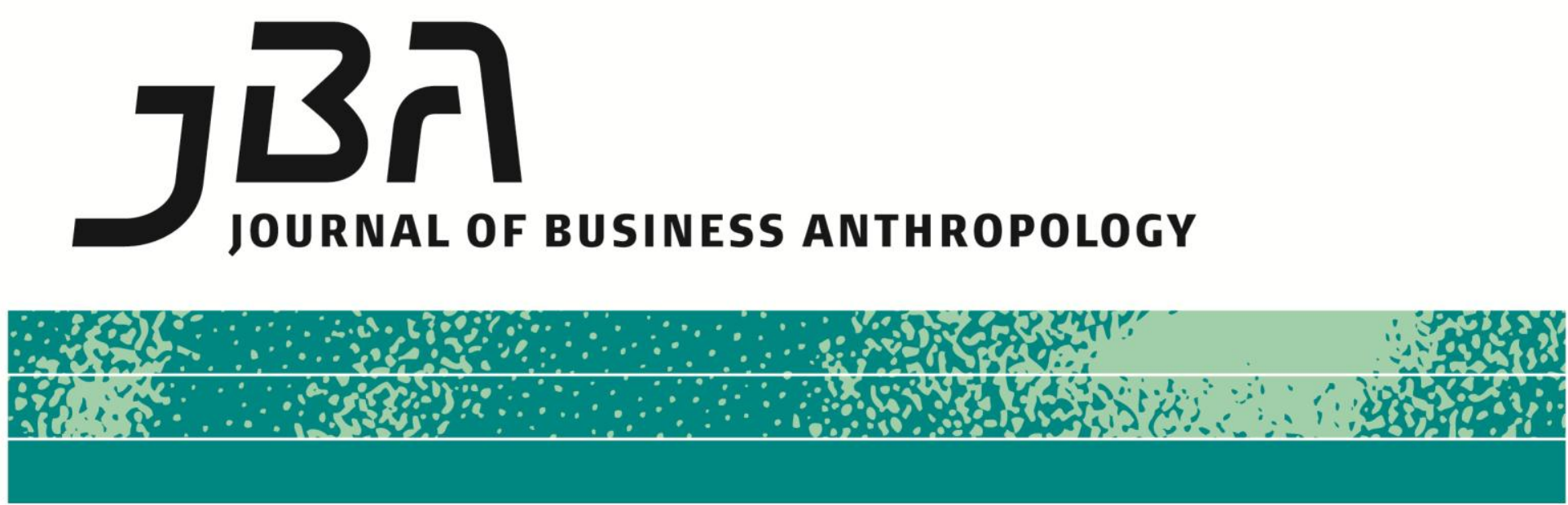

\title{
Business Literature and Understandings of Business
}

James G. Carrier

Business is not just sets of activities and relationships. It is also a cultural category, an aspect of people's understanding of the world and what is in it. Such understandings are interesting in their own right. In addition, however, they are useful for helping us to make sense of people's actions and orientations in various parts of their lives. My purpose here is to illustrate how we might approach those understandings, the sorts of questions we can ask about them, and the sorts of things we might learn from them.

A simple example of those understandings springs from the fact that, for many people, the realm of business is associated with a set of values and practices that is taken to be characteristic of the realm of economy generally. Social scientists have long been interested in people's experiences and views of that economic realm, and especially the ways that they contrast with the social realm. Talcott Parsons (e.g. 1959: 261) pointed to an aspect of that contrast when he argued that these two realms are organised on radically different principles and entail radically different sorts of relationships. David Schneider (1980 [1968]) applied Parsons's argument to American culture when he described how people's understandings of the economic realm, the realm of business, are crucial for their understanding of the family, the essence of the social realm. Less grandly, this distinction can help account for the attraction of fair-
Page 1 of 13

JBA 2(2): 120-132 Fall 2013

(C) The Author(s) 2013 ISSN 2245-4217

www.cbs.dk/jba 
trade foods and other aspects of ethical consumption (Carrier 2012).

People also understand business in terms of companies, their employees, products and the like. They learn about these things because they insistently confront businesses in their economic transactions, and they learn about them as well in tales that are told about businesses in particular and business in general. Those tales are my concern here. I draw on them as they are told in the United States, the country I know best, and I present them with a modest end in view, only to suggest the ways that a consideration of them might be stimulating.

I do so with a brief set of reflections on some of those tales, springing from what I call 'business literature', publications that describe how businesses operate and how they ought to operate. At its broadest, that definition includes things like descriptions and prescriptions about the organisation of supply systems, employment practices in light of labour law, how to organise an advertising campaign and how to keep accounts. Such works tell us something of how businesses are organised and how they operate, but their technical orientation means that they are relatively unlikely to attract a broader readership, and so are relatively unlikely to tell us much about ideas and understandings that have a broader currency.

Those ideas and understandings are more likely to be revealed in a different sort of business literature, my focus here. That is writing intended for a more general readership that presents business activities. It can range from newspaper articles about a firm or industry to books that offer extended studies of firms or events in the commercial world. Perhaps the most visible form this sort takes is books that may have been intended for upper-level managers and those who aspire to join them, but that have attracted broader interest, the sort of things that are part of Wall Street reading lists (e.g. Sorkin 2013).

That broader interest suggests something about the relationship of those works to public understandings of business. Firstly, it suggests that those works do not simply repeat what everyone knows, for if they did so, they would be unlikely to generate much interest. Secondly, however, it suggests that they roughly conform to those public understandings, for if they did not, they would likely be relatively incomprehensible to the general public and hence would not attract readers. Taken together, these observations suggest that this sort of business literature would be a useful point of entry to common understandings of the nature of business.

I said that my purpose here is only to suggest the sorts of directions in which a consideration of that literature might lead. That means I do not intend a thorough and careful analysis of that literature. It is vast and I have neither the knowledge nor the wit for 
such a task. Equally, because my purpose is to be provocative, I attend only to aspects of that literature itself. I do not attend to who reads it, how and why they do so, what they learn from it, and how it affects their thinking. Such analysis would be necessary for any sound description of the literature and its effects, and if my provocation here works, people will be motivated to undertake that analysis.

I said that the sort of business literature that concerns me is likely to present novel observations or interesting tales, presented against a background of common understandings of what business is and how it operates. While those observations and tales deserve attention, here I am concerned with that background, and with the assumptions that are part of it. These assumptions amount to understandings that people are likely to take as fairly self-evident, simply part of the way things are, and hence not requiring explicit consideration. Such assumptions are the sort of thing that, as Pierre Bourdieu (1977: 167, emphasis omitted) put it, 'goes without saying because it comes without saying', which means that they are part of what he (1977: 164) calls the orthodox, that which commands the assent of thoughtful people, or doxa, that which is taken for granted as part of the natural order of things. The background assumptions that concern me revolve around the general conception of the world of business as one of firms, each of which is run by a boss and each of which is in competition in the market with entities like itself.

\section{The firm and the boss}

In business literature it is common to associate the firm with the boss, often to the extent that the boss subsumes the firm. This is especially so in the case of firms that become newsworthy, usually because they are taken to be extraordinarily successful, and as I said, I take business news as part of business literature, especially when it appears in mass media. One obvious example of the newsworthy firm is Apple Inc., subsumed under the identity of its late boss, Steve Jobs. An earlier example is General Electric Company in the United States, often subsumed under the identity of Jack Welch, its boss in the 1980s and 1990s.

One form of this conflation of boss and company was laid out in detail by Paul Hawken, one of the bosses of Smith \& Hawken, an American company that sold garden paraphernalia between 1979 and 2009. Hawken was not just one of the bosses of the firm. In addition, he was a business consultant who was the focus of a series of television programmes in the $1980 \mathrm{~s}$, which he then turned into a book, Growing a business (Hawken 1987). As I have discussed his presentation of the relationship between business and boss in that book at some length elsewhere (Carrier 1997b), I will be brief here. For Hawken, the business is the extension and expression of the boss, 
just as Apple was presented as the extension and expression of Steve Jobs. As Hawken (1987: 61) put it, the business is 'an uncluttered expression of yourself [i.e., of the boss].' This association of company and boss recurs through his book, perhaps most notably when he (1987: 60) relates the decision to found Smith \& Hawken. His tale includes moral anguish, five hours in a bath trying to figure out what to do and, ultimately, the conclusion that it was all really very simple: he and his partner had given their word and had to honour it. Hawken's recounting of his bath presents an image very different from tales of Steve Jobs and Jack Welch, and those images reflect different sorts of ideas about what makes a good boss. The differences, however, rest on a common assumption: in crucial ways, the company is the boss.

This association of company with boss is apparent also in accounts of important commercial events. One such account is by two reporters at The Wall Street Journal, Bryan Burrough and John Helyar. They wrote a book that reached a broad readership, Barbarians at the gate (1990). It is the story of the take-over of the American firm RJR Nabisco in 1988, at the time the most costly company acquisition in history. That book is a complex tale, full of company directors, managers of banks and investment funds and all the rest, but the core of the story revolves around a boss. He is Ross Johnson, head of RJR Nabisco at the time of the take-over. Johnson lost his job as a result of the acquisition and it turned out that RJR Nabisco and many of its employees suffered because of Johnson's actions. It appears, then, that what often holds for the very successful, like Jobs and Welch, holds also for the unsuccessful: the story of the company is the story of the boss.

There are good reasons why company and boss should be associated in this way in the business literature. At the most general level, it helps to make a good story, one that revolves around individuals, clear protagonists who drive events. That sort of story is likely to be more appealing, and hence attract a broader readership, than one that revolves around more abstract processes and relationships, if only because it allows for a presentation of events that is simpler, and hence more compelling (Carrier 2009). More substantially, the association of boss and company accords with an important American belief in the virtues of being one's own boss and running one's own business (Berthoff 1980), the sort of belief that helps explain a regular feature of the business section of The New York Times, 'You're the boss' (e.g. Emerson 2013). This association takes institutional and financial form in a practice that became increasingly common in the final third of the twentieth century: the linking of the boss's pay to the performance of the company. This was advocated as a way to encourage bosses to act to improve the company's performance on the stock market, shareholder value, 
rather than being the steward of an enterprise in which many sorts of people have an interest. Whatever its logic, however, it reflected and solidified the conflation of company and boss.

I have invoked Bourdieu's point about the importance of what goes without saying. That point takes on additional significance when we recall that it is part of what he says about misrecognition, in which the society engages in 'the naturalization of its own arbitrariness' (Bourdieu 1977: 164). To say that misrecognition is the naturalisation of the arbitrary is to say that it involves treating as part of the natural order of things a set of processes and relationships that are arbitrary in the sense that they are social conventions. Bourdieu, then, suggests that we should approach what goes without saying in terms of what it obscures and the assumptions on which it rests, but that it does not explain or justify, part of the process by which those things come without saying.

Perhaps the most obvious thing that the conflation of boss and firm omits is the fact that the firm is an institution that survives because a variety of people 0 within it work in a complex division of labour. These people must figure out what they need to do and figure out how to do it, a process that can involve coping with and correcting the mistakes of their superiors. This is the sort of thing that is described in a different sort of business literature by Scott Adams, whose cartoon character Dilbert (www.dilbert.com) provides one of the most sardonic commentaries on American business. Moreover, the ways that people figure out their work and how to do it is not something that is always apparent to the firm's management. As David Halle (1984) shows in his study of a chemical works in the US, those who are interested in their work may well find out ways to do it better and more easily than management, or the procedure manual, dictates - improvements that may be neither visible nor comprehensible to their superiors. Put in different terms, the personification of the company in the boss ignores the importance of the routine operations on which the company relies for its survival, as well as the employees who carry out these operations.

In one sense, this ignoring is not surprising. It reinforces the conceptual boundary between management and labour - in this case the people who direct the company and the people who are supposed to carry out those directions - and it does so by making that labour invisible. As well, it reinforces an assumption that has attracted less attention than the boundary between management and labour. That is the assumption that the boss can control the company, or, indeed, that a company with more than a handful of workers can be controlled in any straightforward way.

A different sort of business literature points to some of the reasons why that control is problematic. It does so when it identifies 
the attributes of people's tasks and work relations that affect how they go about their jobs, effects that exist independently of the policies and directives through which the company seeks to control its workers. Two fairly old examples of this different sort of business literature are Gerald Mars's Cheats at work (1982) and Terrence Deal and Allan Kennedy's Corporate cultures (1982). Mars is concerned with the nature of the work group, especially the degree to which it is structured and bounded, and he relates these attributes to the ways that people in those groups behave in their work. Deal and Kennedy are concerned instead with the importance of the decisions that people typically make in their jobs and how long it normally takes them to find out if the decisions were good or bad, and they relate these attributes to the ways that people carry out their tasks. While Cheats at work and Corporate cultures are interesting in the tales that they tell and the arguments that they make, they are pertinent here because they point to forces within the firm that exist fairly independently of company policy and that affect the way that workers carry out their tasks. In doing this, they suggest that the image of the boss that I have described can seriously exaggerate the boss's ability to control the firm's employees, and hence to control what the firm does.

Something else that attests to the uncertain nature of control of the firm is the recurring efforts that companies have made to secure it. Those efforts range from things like the moving assembly line and the principles of scientific management early in the twentieth century to things like flat company structure and quality circles late in that century, efforts overlain by the oscillation between organising the company in terms of product lines and in terms of function or, indeed, in adopting a matrix structure that combines the two. If asserting and maintaining control were reasonably straightforward, these sorts of changes in policy and practice would not be necessary. It seems, then, that those who focus on the boss have absorbed but not understood Weber's model of bureaucratic organisation. They have absorbed his idea of a bureaucracy as a machine that responds impersonally and efficiently to the commands issued by those at the top. They have not understood that Weber was presenting an ideal type that exists nowhere. Outside the fanciful world of the organisational chart, firms of any size are likely to resemble Weber's bureaucracy less than they do a feudal system, in which different parts of the firm have their own interests and orientations and sources of support and influence.

Often enough, those parts have to be induced rather than commanded, tolerated or even worked around, rather than controlled.

The assumption that a firm can be controlled in a fairly straightforward way helps account for the growing attention late in the twentieth century to the idea of 'best practice', the belief that 
there is a best way for firms to do things. This marks that assumption because it rests on two further assumptions. The first is that best practice is objectively valid. The second is that firms deviate from it because they do not know what it is, and that if they did know of it they would be able to implement it. Another piece of business literature was influential in the emergence of the idea of best practice, Thomas Peters and Robert Waterman's In search of excellence (1982). In this book, the authors identified 32 firms that were said to be very successful and identified eight practices that were central to their success.

Like many works in the business literature that present accounts of successful firms, In search of excellence has a methodological flaw. It investigates successful firms and adduces practices that are taken to account for that success, but does not investigate other firms that employ these practices to see if they also are successful. This flaw means that the claim that a successful company does $\mathrm{X}$ may be true, but is no ground for assuming that $\mathrm{X}$ causes that success. Even so, works like In search of excellence remain popular, and one reason that they are so is that they reflect and reinforce the assumption that firms resemble Weberian bureaucracies that respond to the decisions of the bosses who run them.

In saying this I do not mean that conforming to best practice makes no difference. In fact, it is likely that conformity, or at least appearing to conform, increases the chance that a firm will do well. The reason, however, may well not be the one that underlay In search of excellence. Paul DiMaggio and Walter Powell (1983) point to that reason in their consideration of the fact that companies in an industry tend to be organised in the same way: steel firms tend to resemble each other, as do banks, mining companies and the rest. DiMaggio and Powell say that this conformity commonly is justified by arguments about the firm and its profitability: steel firms adopt the same organisation because it is the best way to organise and run a steel firm. They argue, however, that a different factor is at least as important, a factor that one might call more social than technical, more concerned with commercial fashion than with economic rationality. That is, that firms that appear to conform to industry fashion will be taken more seriously than those that do not. Having a firm be taken seriously is important. Banks will be more willing to lend to it; suppliers and purchasers will be more willing to deal with it. In pointing to the complex factors that shape the firm and that are external to it, what DiMaggio and Powell say further challenges the literature's focuses on bosses and the firms that they control. 


\section{The firm's world}

Bosses may be better or worse; Jobs at Apple and Welch at GE, even Hawken at Smith \& Hawken, are likely to stand scrutiny better than Johnson at RJR Nabisco. But the focus on Johnson in Barbarians at the gate, like the focus on Jobs, assumes and solidifies the centrality of the boss. I turn now to a different matter, the world in which the firm exists. In much of the business literature, that world is one of other bosses in charge of other firms, competing in their efforts to increase their profit and so be successful bosses of successful firms.

There are many ways that a company can increase its profit, but what commonly attracts attention is innovation, especially of a new product, the sort of thing that often is presented as the key to Jobs's success at Apple. Innovation needs to be distinguished from improvement. That is the gradual increase in efficiency, and hence profitability, that comes from figuring out better ways to do what the company already is doing. Innovation, on the other hand, entails producing something new that leads to a qualitative improvement in the company's position in a competitive market. In the case of Jobs, it was the Mac computer with its graphical user interface, which was intended as a qualitative improvement over the competing computers on the market, especially those that used the operating system produced by Microsoft, another company subsumed under the identity of another boss, Bill Gates.

Innovation is the focus of its own thread in the business literature. A popular example of this is by Clayton Christensen, The innovator's dilemma (1997), which describes how difficult it can be to maintain a firm's position in the face of innovative competitors. This book is interesting in part because the change in its title reflects the assumptions that the boss subsumes the firm and that firm can be controlled. Its original subtitle was when new technologies cause great firms to fail, which stressed the historical analyses that are the core of the work and the intellectual puzzle that those analyses posed. However, later editions abandoned that stress and had the subtitle the revolutionary book that will change the way you do business.

It is understandable that the successful boss is seen as one who innovates in a competitive market, for a successful innovation brings substantial benefits. It can give the boss and the company 'brand leadership', perhaps even a 'category buster', producing something that comes to be identified with, or even defines, a class of product. Examples from the United States include the Model T automobile that Ford produced, which came to define ordinary people's cars, Campbell's soup, which came to define ready-made soup, and Pampers, which came to define disposable nappies. Having such a product makes it more likely that the firm will be a success, for it can charge a premium for that product based on the appeal of the brand, 
independently of the quality of the product.

As with the conflation of the company with the boss, so the image of the boss as innovator that I have sketched is a partial one, and as with that conflation, the partiality is revealing. In particular, the stress on innovation directs attention outward, from the company to the market where it competes with other companies. One effect of looking outward echoes the effect of conflating the company with the boss, for it sleights the fact that the company is an institution. As well, it portrays the source of company profit and success in ways that echo common assumptions about the virtues of the free market, full of potential purchasers who are ready to buy from firms that offer new and appealing products, and hence encourage efficiency and innovation (Carrier 1997a: 1-4). This sort of view is not just found in popular American culture, of course. It is part of an important stream in economics, illustrated recently in Mass flourishing: how grassroots innovation created jobs, challenge and change, by an economist awarded a Nobel Prize, Edmund Phelps (2013).

The image of the successful boss as one whose innovation serves consumer demand focuses on the product and its virtues. It assumes, of course, that purchasers are concerned with the material qualities of what is on offer at what price, which is central to The innovator's dilemma. The business literature is not alone in this assumption. It is what underlies organisations like the Consumers Union (now Consumer Reports) in the US and the Consumers' Association in the UK, which regularly inform their members of the prices and material attributes of various items offered for sale. There are potential purchasers who approach objects in this way, and their existence helps to justify the focus on innovation in firms' success. However, this stress on material attributes and prices leaves out a great deal, and so shows a further aspect of the partiality of the stress on innovation.

The main thing that it leaves out is advertising. As Vance Packard (1957) noted long ago, much of this is concerned less with describing a product's material attributes than it is with bestowing desirable images on it. As the old adage has it, you don't buy the steak, you buy the sizzle. And as Ian Jamieson (1980) observed, while some firms in some countries are good at building a better mousetrap, others are better at encouraging the world to beat a path to their door. To return to Steve Jobs, that popular symbol of innovation, his real strength, according to some commentators, lay in his ability to pitch the new products that his company made (Dargis 2013).

What I have said about advertising illustrates how the stress on products and innovation directs attention away from other activities that are important for a company's profit. Some of these activities 
may seem more dubious than advertising a new model of automobile by associating it with young, stylish people with lots of friends. Apple, for instance, certainly produced things that were seen to be innovative. However, a significant part of the company's success was the result of their efforts to reduce costs. They have done this through complex corporate organisation that appears intended primarily to assure that company profits are realised in jurisdictions with corporate tax rates lower than those found in the places where the company is based and where they conduct much of their trade (Schwartz and Duhigg 2012, 2013). As well, they have done this by having much of what they sell produced in countries with cheap labour and weak or non-existent unions and factory regulation (Duhigg and Barboze 2012).

\section{Conclusion}

As I said at the outset, my purpose here has been illustrative and provocative rather than rigorous and demonstrative. Accordingly, I have presented no careful consideration of a survey of business literature and its readers. Rather, I have sought to illustrate the ways that business literature can help us to consider business as a cultural entity, something that is presented, and likely to be understood, in terms of that literature. As part of my intended provocation, I have approached that literature obliquely, concerned not simply with that about which it speaks, but also, and more especially, with that about which it is silent. Borrowing from Bourdieu, I suggested that those silences point to the taken-for-granted, what goes without saying, because it comes without saying.

The speaking and the silence that I have used to illustrate how we might approach business literature revolve around the conflation of firms and bosses, and see them as confronting other firms with other bosses, all seeking product innovation in their competitive struggles. While speaking of firms in terms of their bosses can be taken as simple synecdoche, at times the image of the boss subsumes the identity of the company almost entirely. Similarly, speaking of innovation in competitive struggle can be taken as synecdoche for conventional competition for market advantage. However, the stress on innovation is so common that more seems at work than the desire for a simple shorthand.

Equally broadly, those silences elide the institutional nature of the firm, the fact that firms rely on their workers and that firms of any size are complex and, often enough, unruly, so much so that no boss can run it, or perhaps even grasp it. They also elide the ways that a firm's success springs from much more than the attributes and prices of what it offers to potential purchasers. Anything that persuades those purchasers to buy, like anything that reduces a firm's 
costs, will contribute to the firm's profit, which is the definition of its degree of success.

I want to close by speculating on why the sorts of images, and their silences and assumptions, that I described are as popular as they are, given how implausible they are. Perhaps the best way to begin to answer that question is to observe that those images appear to relate to very small businesses. In them, bosses are relatively able to grasp what the business is and to shape its operations, so that the conflation of boss and firm is plausible. Appropriately, in Growing a business, Hawken's tales are mostly about founding Smith \& Hawken, not about running it as a fairly large retail mail-order firm. As companies become larger, however, those images become less reasonable. The same is true once a company passes out of the hands of the founder: one of the most difficult challenges any company faces is surviving the departure of the person who started it.

It appears, then, that the images I have described reflect something like the assumption, or perhaps the wish, that all businesses are like small businesses. This is the personal world that concerned Adam Smith (1776: Bk 1, Ch 2, Para 2), when he observed that it is not from the benevolence of the butcher, the brewer, or the baker, that we expect our dinner, but from their regard to their own interest.' However, it is hardly the world that most people who read these words, or read the business literature, confront. That world is one in which we get our dinner from employees who may take our money, but who own neither the things we buy nor the money we give them. In its turn, this personal view reflects the positive value placed on the individual and individual autonomy that is especially strong in the United States.

\section{References}

Berthoff, Rowland 1980. Independence and enterprise: small business in the American Dream. In Small business in American life (ed.) Stuart W. Bruchey, pp. 28-48. New York: Columbia University Press.

Bourdieu, Pierre 1977. Outline of a theory of practice. Cambridge: Cambridge University Press.

Burrough, Bryan and John Helyar 1990. Barbarians at the gate: the fall of RJR Nabisco. New York: Harper \& Row.

Carrier, James G. 1997a. Introduction. In Meanings of the market (ed.) J.G. Carrier, pp. 1-67. Oxford: Berg.

Carrier, James G. 1997b. Mr Smith, meet Mr Hawken. In Meanings of the market (ed.) J.G. Carrier, pp. 129-57. Oxford: Berg. 
Carrier, James G. 2009. Simplicity in economic anthropology: persuasion, form and substance. In Economic Persuasions (ed.) Stephen Gudeman, pp. 15-30. Oxford: Berghahn.

Carrier, James G. 2012. Introduction. In Ethical consumption (eds) J.G. Carrier and Peter Luetchford, pp. 1-35. New York: Berghahn.

Christensen, Clayton 1997. The innovator's dilemma. Boston: Harvard Business Review Press.

Dargis, Manohla 2013. Portrait of the artist behind Apple. The New York Times (15 August). movies.nytimes.com/2013/08/16/movies/ashton-kutcher-in-abiopic-about-steve-jobs.html

Deal, Terrence E. and Allan A. Kennedy 1982. Corporate cultures. Reading, MA: Addison-Wesley.

DiMaggio, Paul and Walter Powell 1983. The Iron Cage revisited: institutional isomorphism and collective rationality in organizational fields. American Sociological Review 48 (2): 147-60.

Duhigg, Charles and David Barboze 2012. In China, the human costs that are built into an iPad. The New York Times (26 January). http://query.nytimes.com/gst/fullpage.html?res=9C02E2D71438F93 5A15752C0A9649D8B63

Emerson, Melinda F. 2013. How to run a Facebook commerce store. You're the Boss, The New York Times (2 August).

http://boss.blogs.nytimes.com/2013/08/02/how-to-run-a-facebookcommerce-store/

Halle, David 1984. America's working man. Chicago: University of Chicago Press.

Hawken, Paul 1987. Growing a business. New York: Simon and Schuster.

Jamieson, Ian 1980. Capitalism and culture: a comparative analysis of British and American manufacturing organizations. Sociology 14 (2): 217-45.

Mars, Gerald 1982. Cheats at work. London: George Allen \& Unwin.

Packard, Vance 1957. The hidden persuaders. New York: David McKay Company.

Parsons, Talcott 1959. The social structure of the family. In The family (ed.) Ruth Nanda Anshen, pp. 241-74. New York: Harper and Row.

Peters, Thomas J. and Robert H. Waterman, Jr 1982. In search of excellence. New York: Harper and Row.

Phelps, Edmund 2013. Mass flourishing. Princeton, NJ: Princeton University Press. 
Schneider, David 1980 (1968). American kinship. (Second edition.) Chicago: University of Chicago Press.

Schwartz, Nelson D. and Charles Duhigg 2012. How Apple sidesteps billions in taxes. The New York Times (28 April). www.nytimes.com/2012/04/29/business/apples-tax-strategy-aimsat-low-tax-states-and-nations.html?pagewanted=all\&_r $=0$

Schwartz, Nelson D. and Charles Duhigg 2013. Apple's web of tax shelters saved it billions, panel finds. The New York Times (20 May). www.nytimes.com/2013/05/21/business/apple-avoided-billions-intaxes-congressional-panel-says.html?pagewanted =all

Smith, Adam 1776. Inquiry into the nature and causes of the wealth of nations. Numerous editions.

Sorkin, Andrew Ross 2013. The essential Wall Street summer reading list. The New York Times (1 July). http://dealbook.nytimes.com/2013/07/01/wall-street-must-readsfor-everyone/? $\mathrm{r}=0$

James G. Carrier has taught in Papua New Guinea, the United States and the United Kingdom, and done research in those countries as well as in Jamaica. That research has focussed on economy and political economy and their relationship with other areas of life. His recent publications include $A$ Handbook of Economic Anthropology (Edward Elgar, 2005; revised edition 2012), Virtualism, Governance and Practice (edited with P. West, Berghahn, 2009), Ethical Consumption (edited with P. Luetchford, Berghahn, 2012) and The Handbook of Sociocultural Anthropology (edited with D. Gewertz, Bloomsbury, 2013). He may be reached at jcarrier@brookes.ac.uk 